\title{
artigos
}

DOI: 10.11606/issn.2318-8855.v6i6p125-148

\section{Abdias do Nascimento e Paulo Freire: dizeres, saberes e experiências na África Ocidental (1975-1988)}

Elisa Ferreira Teixeira ${ }^{*}$

Resumo: O presente artigo tem por objetivo demonstrar e argumentar as narrativas sobre 0 colonialismo e racismo a partir de sujeitos que vivenciaram as experiências africanas e brasileiras e, consequentemente, discutiram as questões raciais de cada contexto. Sendo assim, serão abordadas as histórias de Paulo Freire e de Abdias do Nascimento, que foram intelectuais importantes por conta dos seus discursos e práticas revolucionárias nesses ambientes. Através do estudo e da comparação das obras escritas por esses estudiosos, cujos títulos são: Cartas à Guiné-Bissau (1975-1977) e A África ensinando a gente (1978-1988), de Paulo Freire, O genocídio do negro brasileiro (1978) e Sitiado em Lagos (1981), de Abdias do Nascimento, será possível desvendar e entender as ações e as relações de cada um para com os problemas da população negra e as suas respectivas lutas. Também será viável ter a percepção de ambos como agentes sociais importantes para a construção das representações históricas sobre a condição do negro na África e na diáspora.

Palavras-chave: Intelectuais antirracistas; Colonialismo; Racismo.

\section{Introdução}

Este artigo é direcionado a tratar sobre as narrativas do colonialismo e racismo contemporâneos de uma perspectiva comparatista, a partir disso será possível enxergar as experiências africanistas dos intelectuais antirracistas abordados, que trazem à tona discussões importantes sobre as temáticas raciais no decorrer do século XX. Como já mencionado, nesse estudo tem-se o foco em dois intelectuais: Paulo Freire e Abdias do Nascimento, que foram sujeitos históricos atuantes e participantes do contexto de descolonização africana e combate ao racismo.

\footnotetext{
* Graduada em História pelo Centro de Ciências Humanas, Letras e Artes da Universidade Federal da Paraíba. Contato: elisaferreira95@gmail.com.
} 


\section{artigos}

Elisa Ferreira Teixeira

Antes de demonstrar a participação de ambos no contexto abordado por esse artigo, é importante trazer à tona a significância desses dois estudiosos tanto para o movimento negro como para a educação.

Abdias do Nascimento (1914-2011) tornou-se um dos mais reconhecidos ativistas das causas da população negra por conta dos seus inúmeros projetos e de sua participação em ações que possibilitavam novos olhares acerca da história e cultura afro-brasileira. Desde a sua infância no interior de São Paulo, em Franca, Abdias não se ajustava ao meio em que vivia, principalmente no que diz respeito ao preconceito racial, pois ele nunca ficava calado perante as discriminações e sempre almejava uma melhora de vida para a população negra. E, com o decorrer do tempo, principalmente com a sua mudança para a cidade de São Paulo, essa "revolta" fez com que ele se interessasse pela militância. Como exemplo, tem-se a participação dele na Frente Negra Brasileira, uma das maiores organizações negras de sua época. Por conta do seu ativismo e das suas lutas, ele virou "carta marcada" para polícia e, dessa maneira, acabou mudando-se para o Rio de Janeiro. Um ponto muito importante da estada de Abdias no Rio de Janeiro foi o encontro dele com as raízes negras, ou seja, a cultura negra. É também na capital carioca que ele desenvolveu e concretizou um dos seus mais importantes projetos: o Teatro Experimental do Negro (TEN), no ano de 1944. O TEN buscava resgatar os valores da pessoa humana e da cultura negro-africana, negados por uma sociedade dominante. Com o golpe militar de 1964, no entanto, a militância negra enfrentou forte repressão por parte dos governos. É por causa dessa conjuntura que Abdias se exilou nos Estados Unidos, e é nesse ambiente que ele conseguiu empreender a sua luta a favor dos afro-brasileiros e africanos a nível internacional. As experiências e as relações que foram empreendidas no cenário acadêmico, em palestras, seminários e na atividade política militante em diversos países, como a África, inspiraram os seus estudos e reflexões acerca das relações raciais. Os livros O genocídio do negro brasileiro (1978) e Sitiado em Lagos (1981) refletem muito bem esse momento da trajetória desse pensador.

Paulo Freire (1921-1997) é considerado um dos pensadores mais notáveis da pedagogia, por conta das suas formulações e projetos para fazer com que os inferiorizados pudessem ter acesso e 


\section{artigos}

Abdias do Nascimento e Paulo Freire: dizeres, saberes e experiências na África Ocidental (1975-1988)

conscientização a partir da educação. O pensamento de Paulo Freire deve ser entendido como sendo criado em um contexto de vivência no Nordeste brasileiro (especificamente em Recife, PE), onde havia uma alta taxa de analfabetos, ou seja, a "cultura do silêncio" ainda era muito predominante e era preciso que alguém lhes desse a palavra para que pudessem se tornar sujeitos atuantes na construção do país e, a partir disso, superar a amargura do colonialismo. Em suas várias obras temse a visão da educação como sendo algo libertário e que acarretará mudanças, ou seja, mudança de uma sociedade de oprimidos para uma sociedade de iguais. Paulo Freire, extrapolando a área acadêmica e institucional, engajou-se também nos movimentos de educação popular do início dos anos 60. Foi um dos fundadores do Movimento de Cultura Popular (M.C.P.) do Recife, onde o objetivo era a valorização da cultura popular e com isto inserir as massas populares na sociedade brasileira. No seu processo de alfabetização havia a necessidade de formar cidadãos conscientes e críticos e, por isso, quando a ditadura foi implantada enxergaram um grande problema nesse estudioso. No ano de 1964, Freire partiu para o exílio na Bolívia e logo depois se mudou para o Chile, onde permaneceu até 1969. Na metade do ano de 1969 mudou-se para Cambridge, Massachusetts, dando aulas sobre suas próprias reflexões na Universidade de Harvard, como professor convidado e lá permaneceu até 1970. Em seguida, foi para Genebra para ser Consultor Especial do Departamento de Educação do Conselho Mundial de Igrejas e, por conta desse contexto, ele percorreu vários lugares, como a África, Ásia, Oceania e América. Ele ajudava os países que haviam acabado de conseguir sua independência política a sistematizarem o seu sistema educacional. Os livros Cartas à Guiné-Bissau (1975-1977) e A África ensinando a gente (1978-1988) demonstram de maneira efetiva e prática as experiências de Freire nesses cenários.

O contexto adotado por esse artigo diz respeito à descolonização do continente africano e consequente solidificação do protagonismo negro e pensamento antirracista. O colonialismo trouxe inúmeras consequências para a população negra e, como afirmado por Aimé Césaire, também possuiu o poder de desumanizar, pois o colonizador passa a se habituar a ver o outro como sendo um animal, a tratá-lo como tal, não enxergando que ele próprio também se transformou em um animal. Sendo assim, o colonialismo desciviliza e desumaniza tanto o colonizado quanto o colonizador. Essas atitudes representam os principais pilares da ideologia racista, que trouxe consigo 


\section{artigos}

Elisa Ferreira Teixeira

a necessidade de inferiorização e degradação da raça negra. E os resultados do "processo civilizatório" foram sociedades esvaziadas, culturas desprezadas, crenças e religiões acabadas e muitos outros desastres. Com a luta e a resistência negra, a emancipação foi se tornando realidade e importantes acontecimentos e mudanças vieram à tona. Paulo Freire e Abdias do Nascimento fizeram parte dessas transformações, pois foram sujeitos históricos atuantes e participantes do contexto de descolonização africana e combate ao racismo.

Na segunda metade da década de 1970, o pedagogo Paulo Freire construiu diálogos profundos com a experiência africana, especialmente a partir de Guiné-Bissau, e posteriormente as "missões pedagógicas" também chegaram a outras localidades: Angola, São Tomé e Príncipe. O engajamento político-educacional de Paulo Freire nos países africanos no período pós-colonial foi de grande importância, pois é apresentada uma visão dos desafios de reconstrução nacional, os quais se iniciam a partir de um processo de lutas pela independência do colonialismo e do aprendizado da autonomia pelos colonizados. Essa conjuntura passou a ser um ambiente favorável para que Freire colocasse à prova os pressupostos teóricos e práticos de sua pedagogia políticolibertadora e, a partir disso, conseguir que os vários povos africanos pudessem finalmente escrever a sua própria história. Quase ao mesmo tempo, o ativista negro Abdias do Nascimento denunciou a ditadura no Brasil por atos racistas e discriminatórios contra os intelectuais negros e a população negra em geral. Entre os vários escritos de Abdias do Nascimento podemos encontrar a demonstração e a denunciação dos vários problemas e aparências que o nosso país quer esconder, um deles é o racismo. Esse pensador escreveu verdades amargas que até os dias atuais têm um peso relevante na nossa vivência, verdades estas que colocam à tona os reais problemas do negro neste espaço e buscam estabelecer novas formas de percepção e análise da realidade social em que estão inseridos. Abdias do Nascimento, através de seus escritos e experiências, nos mostrou a luta e a resistência negra contra a discriminação e exclusão racial. Havia também o objetivo de proporcionar maior visibilidade e oportunidade ao negro numa sociedade em que as marcas do racismo ainda estão muito latentes. 


\section{artigos}

Abdias do Nascimento e Paulo Freire: dizeres, saberes e experiências na África Ocidental (1975-1988)

Portanto, o protagonismo negro de importantes sujeitos históricos, o pensamento antirracista e as ações revolucionárias foram fundamentais para a constituição de uma nova interpretação da África e também do Brasil. Esses dois intelectuais irão nos mostrar que entrar em contato com as questões africanas é entender as nossas origens, é nos reconhecer na cultura e nas histórias das nações africanas, mas também refletir sobre as marcas africanas no Brasil. Impõem-nos a necessidade de discutir o racismo e as muitas formas de opressão, violência e exclusão a que são submetidos os afrodescendentes no Brasil e fora dele. E com isso, temos um espaço para a resistência e para a reflexão, pois é a partir da conscientização que se constrói a esperança e se caminha para a autonomia e para a igualdade na diversidade.

\section{Conexão África-Brasil: experiências de Abdias do Nascimento e Paulo Freire}

O encontro de Paulo Freire com a África acontece simultaneamente ao contexto em que se dão vários movimentos de independência em países daquele continente. Freire se vê envolto em um ambiente recém-libertado tanto politicamente quanto economicamente, e percebe as várias necessidades daquele povo, que precisaria obter novamente a sua autonomia, a sua história.

No livro Cartas à Guiné-Bissau, Freire narra as suas experiências na alfabetização daquela sociedade, levando em consideração o contexto vivenciado pela África, que estava em um processo de reconstrução nacional. Diante dessa conjuntura, a educação era considerada:

(...) um ato político, em cujo processo os alfabetizandos se engajam com a ajuda dos animadores-alfabetizadores - enquanto militantes uns e outros, no aprendizado crítico da leitura e da escrita e não na memorização mecânica e alienante de sílabas, palavras e frases que Ihes fossem doadas. (...) Numa perspectiva revolucionária, pelo contrário, impõe-se que os alfabetizandos percebam ou aprofundem a percepção de que o fundamental mesmo é fazer história e por ela serem feitos e refeitos e não ler estórias alienantes (FREIRE, 1978, p. 27).

Sabendo que a educação estava inserida em um contexto de reestruturação, é importante esclarecer que a alfabetização dessas populações tinha o objetivo de: 


\section{artigos}

Elisa Ferreira Teixeira

(...) integração do trabalho produtivo às atividades escolares normais, no intuito de combinar trabalho e estudo, de tal maneira que aquele que fosse, tanto quanto possível, constituindo-se como fonte do último, em unidade com ele. Na medida em que essas experiências se forem sistematizando e aprofundando é possível fazer derivar da atividade produtiva, cada vez mais, os conteúdos programáticos de " $n$ " disciplinas que, no sistema tradicional, são "transferidos", quando são, verbalistamente. Em certo momento, já não se estuda para trabalhar nem se trabalha pra estudar; estuda-se ao trabalhar. Instala-se aí, verdadeiramente, a unidade entre a prática e a teoria (FREIRE, 1978, p. 25).

Então, a experiência de Paulo Freire na África foi de profunda importância para atrelar o processo educativo ao sistema de produção material e cultural. Além da vinculação entre produção e educação, tem-se também a luta pela descolonização através da união entre teoria e prática. Essa preocupação em unir o ensino ao trabalho é notada nos Cadernos de Cultura Popular, caderno este que foi redigido durante a experiência de alfabetização em São Tomé e Príncipe, e trouxe à tona importantes temas inerentes ao trabalho, à saúde e à higiene, obtendo através dessa junção um sistema integrado de educação. A diversificação e a expansão do trabalho coletivo no campo constituíam uma valorização das áreas do conhecimento e das habilidades práticas. A educação já não era mais considerada uma atividade singular, desligada da vida e da produção, mas se tornava função do ambiente social e ferramenta de transformação.

Os cadernos e materiais pedagógicos foram usados em várias áreas dos países africanos e conseguiram importantes transformações na maneira de alfabetizar a população, esses relatos foram narrados no livro A África ensinando a gente a partir de depoimentos de personagens envolvidos no processo de reconstrução nacional em Angola, Guiné-Bissau, São Tomé e Príncipe. Como exemplo, usarei uma parte do diálogo entre Sérgio Guimarães, organizador do livro, e Alda do Espírito Santo:

SÉRGIO: Acredita que o trabalho e o apoio que o Paulo Freire deu a São Tomé contribuíram para uma mudança significativa do ensino?

ALDA: Sim, da alfabetização. A alfabetização cresceu duma forma extraordinária! Começamos um processo de alfabetização muito interessante, em que uma grande 


\section{artigos}

Abdias do Nascimento e Paulo Freire: dizeres, saberes e experiências na África Ocidental

parte das pessoas que não sabiam ler tinham um grande interesse na escola, com uma movimentação e tudo mais. E então o sistema começou de fato a crescer. (...)

SÉRGIO: Olhando hoje, tanto tempo depois: acha que esse processo teve bons resultados?

ALDA: O processo teve, foi interessante. Simplesmente, houve uma ruptura (FREIRE; GUIMARÃES, 2003, p. 80).

Nesse contexto, parece clara a tarefa da educação libertadora, tanto no processo revolucionário quanto após a derrubada do regime colonial. Freire soube, como poucos, ler o contexto africano e sistematizar uma concepção de educação que respondesse às necessidades sentidas por militantes e educadores revolucionários. Portanto, não há dúvida de que a contribuição de Paulo Freire representou uma alternativa interessante para reformar o sistema escolar póscolonial africano, pois este não permitiu que a África avançasse em significativos aspectos.

Já a passagem de Abdias do Nascimento pela África teve outro viés. A viagem para o continente africano tinha o objetivo de participação no Festival de Artes e Culturas Negras e Africanas, realizado em Lagos, Nigéria, no ano de 1977, para divulgação do seu ensaio sobre $O$ genocídio do negro brasileiro. O primeiro festival havia acontecido em 1966, em Dakar, Senegal. Os dois projetos representavam a emergência e a afirmação dos países e da identidade africana perante o mundo. Nascimento narra em seu livro Sitiado em Lagos: autodefesa de um negro acossado pelo racismo os acontecimentos ocorridos neste festival, e traz à tona uma vergonhosa veracidade sobre as ações da diplomacia brasileira naquele evento: tentativa de mascarar o racismo e a discriminação que faziam parte do dia-a-dia do negro nesse país. Sabendo da presença de Nascimento nesse encontro, as ações e posições dos participantes da diplomacia foram meticulosamente pensadas para que este intelectual não expusesse as suas opiniões sobre a realidade racial brasileira. A imagem externa do Brasil era muito importante para o governo militar, e por isso as denúncias sobre a questão racial eram altamente indesejadas.

É importante enfatizar que Nascimento já estava sendo vigiado antes do festival: 


\section{artigos}

Elisa Ferreira Teixeira

De fato, aquela minha situação de vigiado começara bem antes de Lagos. Já o consulado brasileiro em Nova York, dois anos antes, havia confiscado ilegalmente o meu passaporte. Minha palavra em diversos encontros internacionais africanos (Kingston, Jamaica; Dar-es-Salaam, Tanzânia; Dacar, Senegal, etc.), expondo o corpo inteiro o racismo, antigo e mascarado, imperante no Brasil há quase 500 anos, motivou aquela violência do nosso governo ditatorial (NASCIMENTO, 2002, p. 264).

Reproduzindo documentos oficiais, Nascimento tenta demonstrar a estratégia utilizada pela diplomacia brasileira para impedi-lo de divulgar suas ideias sobre a "democracia racial" do país. Este pensador constrói suas argumentações a partir das várias evidências coletadas, analisa telegramas trocados entre a embaixada em Lagos, o Ministério das Relações Exteriores do Brasil e os membros presentes na delegação oficial brasileira do evento, e uma nota oficial, escrita pelo embaixador brasileiro na Nigéria, Geraldo Hieráclito Lima. Entre os recados, há algumas passagens interessantes a serem destacadas: "caso houvesse intervenção direta de Nascimento, os delegados deveriam estar preparados para responder a altura"; "caso Nascimento distribuísse seu trabalho aos membros do Colóquio e à imprensa, a embaixada deverá publicar nos jornais uma nota oficial que já estava sendo preparada"; "era necessário pressão juntos aos organizadores para impedir que o trabalho de Nascimento fosse reconhecido em plenário, se baseando no regulamento do evento". É também importante destacar alguns pontos da nota oficial que seria emitida pelo embaixador brasileiro: "os trabalhos de Nascimento são destituídos de valor acadêmico e reconhecidos como de uma natureza panfletária"; "as contradições de Nascimento são gritantes"; "Nascimento é uma contradição viva"; "Nascimento deixou o Brasil para propagar absurdas teorias".

A partir do que foi demonstrado fica perceptível a necessidade da diplomacia brasileira de silenciar Abdias do Nascimento nesse evento. Foram usados todos os meios possíveis para calar a voz deste intelectual, porém, Nascimento conseguiu distribuir cópias do texto que fora rejeitado. Com a divulgação desse material, a delegação brasileira se viu em uma "saia justa", pois se viu pressionada a responder as denúncias de Nascimento. Essa vitória foi de grande importância e relevância para a divulgação e conhecimento da realidade brasileira internacionalmente. 


\section{artigos}

Abdias do Nascimento e Paulo Freire: dizeres, saberes e experiências na África Ocidental

(1975-1988)

Diante disso, tem-se explícito mais um meio de silenciamento e inferiorização da raça negra:

O genocídio que se pratica contra os negros no Brasil segue vários caminhos: tem aquele da morte direta pela fome, pela doença, ou pela ação da polícia; tem o genocídio através da supressão das línguas africanas, da negação, da história, da cultura e das religiões trazidas pelos africanos escravizados; há o genocídio ideológico fundado na supressão das informações demográficas a serviço de elaborações falsificadas como testemunham o Brasil 66 e a nota oficial de Lagos. A simplificação escamoteadora do Itamarati é mais um serviço à política racial predominante - ou seja, o supremacismo branco (NASCIMENTO, 2002, p. 312).

Conforme exposto, é perceptível a força e a resistência nas ações e nos testemunhos de Nascimento, pois mesmo acuado ele conseguiu mostrar a verdadeira face da questão racial no país, e, além disso, também mostrou ao mundo através desse livro todos os meios e planos usados para calá-lo. Com isso, Nascimento nos deixa uma significativa mensagem:

A resistência e a autodefesa do povo afro-brasileiro contra as agressões à sua pessoa física e moral, antes de significar um direito inalienável a ser exercido em toda a sua plenitude, é uma responsabilidade que devemos assumir sob o risco de quaisquer sacrifícios. Mesmo o sacrifício que nos obriga a lidar com matéria destinada ao esgoto no qual se originou. Pois disto se trata neste depoimento: de vermes e dejetos fecais (e oficiais) em atuação transatlântica. De qualquer maneira, não passou de um ledo equívoco do Itamarati supor que o meu silenciamento equivaleria à solução da denúncia racista, tanto no interior do país quanto no exterior. A repressão individual a mim ou a qualquer outro negro ou mulher negra pode retardar, mas não deter, a marcha coletiva atual dos afro-brasileiros rumo à conquista dos seus direitos à liberdade, dignidade, identidade, honra e segurança e bem-estar (NASCIMENTO, 2002, p. 317).

Portanto, o argumento principal das várias obras e atuações de Nascimento ressalta a importância da resistência a qualquer forma de racismo, e de contribuição à história, à memória e visibilidade das tradições africanas e afro-brasileiras. 


\section{artigos}

Elisa Ferreira Teixeira

\section{Ideais pró-africanos nos escritos e nas ações de Nascimento e Freire}

Paulo Freire teve sua vida moldada pela busca de uma educação libertária e que provocasse mudanças, ou seja, mudança de uma sociedade de oprimidos para uma sociedade de iguais. Desde os seus primeiros passos, Freire pensava a educação como prática de emancipação e, em consequência, de descolonização. A valorização da cultura e o respeito à diversidade também são aspectos importantes em suas obras e em seus feitos. Freire propõe uma educação que valorize e respeite as diferenças culturais, os saberes e as experiências de vida dos sujeitos envolvidos nos processos históricos que fazem parte das diversas sociedades existentes. Esses sentimentos de valorização e igualdade foram carregados com ele ao pisar em solo africano:

Faço esta referência para sublinhar o quão importante foi, para mim, pisar pela primeira vez o chão africano e sentir-me nele como quem voltava e não como quem chegava. (...) Daquele momento em diante, as mais mínimas coisas - velhas conhecidas - começaram a falar a mim, de mim. A cor do céu, o verde-azul do amor, os coqueiros, as mangueiras, os cajueiros, o perfume de suas flores, o cheiro da terra; as bananas, entre elas a minha bem amada banana-maçã; o peixe ao leite de coco; os gafanhotos pulando na grama rasteira; o gingar do corpo das gentes andando nas ruas, seu sorriso disponível à vida; os tambores soando no fundo das noites; os corpos bailando e, ao fazê-lo, "desenhando o mundo", a presença, entre as massas populares, da expressão de sua cultura que os colonizadores não conseguiram matar, por mais que se esforçassem para fazê-lo, tudo isso me tomou todo e me fez perceber que eu era mais africano do que pensava (FREIRE, 1978, p. 13-14).

Freire sentia as semelhanças da cultura brasileira com a cultura africana, e enxergava as várias similaridades existentes, que iam desde a comida até o jeito de andar, conseguindo também perceber um traço bem característico e importante em ambas: a resistência. Determinação esta que foi usada contra os diversos propósitos do colonialismo, como exemplo tem-se a invasão cultural, a cultura do silêncio e a obstaculização da presença democrática da população. 


\section{artigos}

Abdias do Nascimento e Paulo Freire: dizeres, saberes e experiências na África Ocidental (1975-1988)

Uma visível estratégia política utilizada pelo colonizador é a de impor a sua linguagem ao colonizado e este, contra a língua estrangeira invasora se defende, falando e mantendo a sua língua, existindo neste processo, uma luta cultural. Os colonizadores afirmavam que a língua dos nativos era usada por selvagens, e por esse motivo deveriam absorver a "língua dos civilizados". Por isso, Freire considera que a linguagem precisa ser considerada um fator importante no debate da identidade cultural. Sabendo disso, a escolha de uma língua que pudesse vir a representar a libertação dos povos africanos seria de grande relevância para a formulação de uma identidade nacional. Segundo Freire, um povo sela a sua libertação na medida em que ele reconquista a sua palavra (FREIRE; GUIMARÃES, 2003, p. 29).

Freire também expõe e discute um dos principais objetivos da educação moldada pelos colonizadores: a desafricanização dos povos nativos. Os meios usados para a internalização dessas visões na população africana é o discurso ideológico da superioridade branca e os assuntos abordados nos meios educacionais, que caracterizam a cultura dos colonizadores. Sabendo disso, Freire propõe a descolonização das mentes e, a partir disso, proporcionar a transformação do sistema educacional e a superação das estruturas de poder eurocêntricas e colonialistas. A reformulação educacional teria os seguintes objetivos:

Neste sentido, a reformulação dos programas de Geografia, de História e de língua portuguesa, ao lado da substituição dos textos de leitura, carregados de ideologia colonialista, era um imperativo. Fazia-se necessário que os estudantes guineenses estudassem, prioritariamente, sua geografia e é não a de Portugal, que estudassem seus braços de mar, seu clima e não o Rio Tejo. Era preciso que os estudantes guineenses estudassem, prioritariamente, a sua história, a história da resistência de seu povo ao invasor, a da luta por sua libertação que lhe devolveu o direito de fazer sua história, e não a história dos reis de Portugal e das intrigas da Corte (FREIRE, 1978, p. 25).

A negação da história e cultura africanas foi desenvolvida pelos colonizadores com o objetivo de impor apenas a história dos brancos, consolidando a visão de que a África não possui história e cultura. Com isso, percebemos que o conhecimento primordial para a população africana é o que 


\section{artigos}

Elisa Ferreira Teixeira

traz à tona a história de sua terra, de sua gente. Conhecer a sua própria história e reconhecer a importância da mesma é um dos caminhos mais profícuos para a consolidação da refricanização da população.

Assim sendo, nota-se a preocupação que Paulo Freire possuía em relação à valorização da história e cultura africanas. Ele desenvolveu maneiras e métodos de fazer com que a população conseguisse se reaproximar e reaprender novamente a sua maneira de viver, a sua língua, a sua cultura e história, que foram tiradas bruscamente pelos colonizadores. Ao incorporar novamente as várias características que fazem parte da vivência de seu país, o homem africano reestabelecerá a ligação que possuí com as suas raízes, e tem-se a volta de uma África livre dos estigmas da colonização.

Além disso, é necessário demonstrar a influência que Amílcar Cabral teve sobre o educador nessa conjuntura, pois sua experiência na África foi muito embasada nos pensamentos desse revolucionário, que lutou pela independência de Cabo Verde e Guiné-Bissau. Como exemplo dessas referências, tem-se a formulação e adesão dos princípios da práxis revolucionária em seus projetos:

(...) a experiência de Paulo Freire na África foi de profunda importância porque, atrelando o processo educativo ao sistema de produção material e cultural, ele radicalizou alguns princípios da sua teoria da educação. Além da vinculação entre produção e educação, que, como veremos depois, emerge claramente nos Cadernos de Cultura Popular, radicalizou-se o princípio da educação como luta de descolonização através da união entre teoria e prática. Freire percebeu com clareza e precisão a presença da práxis revolucionária em Amílcar Cabral. É nessa práxis, ou seja, na relação dialética entre ação e reflexão para a transformação da sociedade, que o educador pernambucano ressalta um elemento fundamental da "pedagogia da revolução" de Amílcar Cabral. A práxis se estende na dimensão pedagógica quando abrange a capacidade de ensinar a aprender através da luta de libertação e da comunhão com o próprio povo. (...) A práxis revolucionária envolve a questão do sistema de produção e da descolonização cultural. Nessa relação entre educação e práxis para a transformação dos modos de produção podemos ver espaços cruciais 


\section{artigos}

Abdias do Nascimento e Paulo Freire: dizeres, saberes e experiências na África Ocidental

da radicalização da filosofia educacional de Paulo Freire ampliada pela leitura que ele fez de Amílcar Cabral (PEREIRA, VITTORIA, 2012, p. 301-302).

Abdias do Nascimento teve a sua trajetória marcada pela participação nas lutas e projetos voltados para a população afro-brasileira, o seu caminho foi marcado pela resistência e pela denúncia dos vários problemas que o nosso país possuí, sendo o racismo um dos maiores obstáculos encontrados em nosso meio. Este intelectual usou de suas obras para a demonstração e a denunciação dos vários problemas e aparências que o nosso país quer esconder. Escreveu verdades amargas que até os dias atuais têm um peso relevante na nossa vivência, verdades estas que colocam à tona os reais problemas do negro neste espaço e buscam estabelecer novas formas de percepção e análise da realidade social em que estão inseridos. Sabendo disso, a obra O genocídio do negro brasileiro mostra-nos o outro lado da história brasileira, face esta que foi omitida e encoberta pela ideologia da democracia racial que propagou a convivência harmônica entre brancos e negros, igualdade de oportunidades sem interferências raciais ou étnicas. Esta obra traz à tona a necessidade de superação da invisibilidade e do silenciamento dos afrodescendentes. Os debates e os relatos deste livro desmontam as ideologias do senso comum ao colocar em xeque a supremacia cultural ocidental que desprezou e "demonizou" outras culturas.

O branqueamento da raça africana é um ponto importante neste livro, o autor deixa claro que o negro era visto como problema para a evolução e melhoramento do país e por isso a cor negra deveria ser erradicada. Os setores dominantes do país, entre o final do século XIX e começo do século $\mathrm{XX}$, almejavam uma sociedade mais branca, voltada para os preceitos europeus e, por isso, a raça negra era vista como empecilho para o alcance desses objetivos. Sabendo disso, a discussão em torno da mestiçagem foi de grande relevância para esse momento histórico, a mestiçagem ora foi muito criticada, ora foi tida como caminho de solução para o problema da raça negra. A mestiçagem como solução tinha o objetivo de criação de uma sociedade unirracial e unicultural, pois haveria a construção de uma sociedade a partir do modelo hegemônico racial e cultural branco, causando o genocídio e o etnocídio de todas as diferentes culturas e raças para a criação de uma nova raça e uma nova civilização. 


\section{artigos}

Elisa Ferreira Teixeira

Os meios usados para o branqueamento são muitos:

Além dos órgãos de poder- o governo, as leis, o capital, as forças armadas, a políciaas classes dominantes brancas têm a sua disposição poderosos implementos de controle social e cultural: o sistema educativo, a várias formas de comunicação das massas- a imprensa, o rádio, a televisão- a produção literária. Todos esses instrumentos estão a serviço dos interesses das classes no poder e são usados para destruir o negro como pessoa e como criador e condutor de uma cultura própria. (...) Tanto os obstáculos teóricos quanto os práticos estão têm impedido a afirmação dos descendentes africanos como íntegros, válidos, autoidentificados elementos constitutivos e construtores da vida cultural e social brasileira (NASCIMENTO, 2002, p. 142).

Sabendo dos problemas vivenciados diariamente pelos afrodescendentes no Brasil, Nascimento formulou um projeto que tinha como objetivo a busca pelo conhecimento e reconhecimento da história e cultura negro-africanas, que ficou conhecido como o Teatro Experimental do Negro, fundado em 1944. O TEN foi pensado e criado por conta de um contexto que ainda discriminava e marginalizava o negro:

O tratamento dramático do descendente africano - estereotipado e Brochado de preto - não constituiu um fenômeno isolado, restrito ao teatro. Muito pelo contrário, trata-se de apenas um fator entre as facetas refletidas pelo contexto geral da sociedade brasileira dominante, da qual o afro-brasileiro não participava e não participa com igualdade de condições e de oportunidades em relação aos demais grupos de diferentes origens étnicas ou raciais. Se o mundo do teatro espelha o mundo de modo geral, o monopólio branco dos palcos brasileiros não é exceção. Ele reflete o monopólio da terra brasileira, dos meios de produção, da direção política e econômica, formação cultural (educação, imprensa, comunicação de massa) tudo tão zelosamente seguro nas mãos de classes dirigentes de origem branco-europeia (NASCIMENTO, 2002, p. 223). 


\section{artigos}

Abdias do Nascimento e Paulo Freire: dizeres, saberes e experiências na África Ocidental (1975-1988)

Dentro desse objetivo, o TEN propunha-se a combater o racismo e propôs novos caminhos para a população afro-brasileira:

O TEN atuou sem descanso como um fermento provocativo, uma aventura da experimentação criativa, propondo caminhos inéditos ao futuro do negro, ao desenvolvimento da cultura brasileira. Para atingir esses objetivos, o TEN se desdobrava em várias frentes: tanto denunciava as formas de racismo sutis e ostensivas, como resistia à opressão cultural da brancura; procurou instalar mecanismos de apoio psicológico para que o negro pudesse dar um salto qualitativo para além do complexo de inferioridade a que o submetia o complexo da superioridade que o condicionava. Foi assim que o TEN instaurou o processo dessa revisão de conceitos e atitudes visando à liberação espiritual e social da comunidade afro-brasileira (NASCIMENTO, 2002, p. 189).

Portanto, o TEN tinha o objetivo de resgatar os valores da pessoa humana e da cultura negroafricana, degradados e renegados por uma sociedade que acredita e propaga a inferioridade da raça negra. Através da educação, da cultura e da arte é consolidada a valorização social do Negro no país. O TEN visava a estabelecer o teatro como um fórum de ideias, debates e propostas que visavam a quebra das estruturas de dominação, opressão e exploração raciais implícitas na sociedade brasileira dominante, nos vários campos de atuação, seja na cultura, economia, educação, política, meios de comunicação, e assim por diante. Assim sendo, o teatro ajudaria a construir um Brasil melhor, justo e democrático, onde todas as raças e cultura fossem respeitadas em suas diferenças, mas iguais em direitos e oportunidades.

Em ambas as experiências desses intelectuais têm-se a visualização do interesse em auxiliar a população afro-brasileira e africana a se encontrar e reencontrar com as suas raízes históricas, com a sua cultura. Ao reconhecerem os problemas causados pelo colonialismo, pela solidificação da cultura branca como sendo a dominante, pelo menosprezo à história negro-africana, eles usam de vários meios para fazer com que as trajetórias e as lutas africanas não sejam ignoradas e muito menos esquecidas. Há algumas diferenças na maneira como aplicaram esses projetos, por exemplo, as mudanças que Freire propôs foram usadas diretamente no continente africano, e esse contexto 


\section{artigos}

Elisa Ferreira Teixeira

estava envolto na questão da reconstrução nacional e consolidação da identidade africana, já as de Nascimento foram usadas no Brasil, e nessa conjuntura havia a preocupação de inserção e valorização do negro na sociedade brasileira, e cada uma dessas experiências tem as suas características e perspectivas, mas também há uma grande semelhança entre uma e outra: a urgência em evidenciar e manifestar a importância que a história e memória africana possuem.

\section{Colonialismo e pensamento antirracista em Nascimento e Freire}

Com base nos escritos e práticas de Paulo Freire e Abdias do Nascimento podemos notar um significativo discurso histórico acerca das décadas em que estão inseridos, anos em que as questões do colonialismo e racismo estavam em foco. A partir da produção histórica desses dois intelectuais é possível visualizar o contexto de ambas as realidades vivenciadas por eles, de um lado temos Paulo Freire demonstrando os obstáculos e os meios encontrados para solucionar os vários problemas de países recém-descolonizados, colocando a educação como um importante caminho para essas resoluções. Do outro lado, temos Abdias do Nascimento mostrando o contexto vivenciado pelo negro no Brasil, ou seja, um ambiente em que o racismo sempre está presente, e por isso a resistência e a força são cruciais para o alcance de uma sociedade igual para todos. Ao vivenciarem essas realidades eles produzem história e participam da história, e colocam as suas opiniões e planos como caminhos para solucionar questões importantes para o alcance da liberdade em seus diversos aspectos.

Em Paulo Freire, a discussão sobre o colonialismo está presente em suas obras pela crítica ao processo opressor da colonização. Segundo Freire, a presença predatória do colonizador destruiu a história e a cultura dos povos invadidos, também trouxe a opressão e a exploração da classe dominante em detrimento das classes menos favorecidas. As experiências que obteve com as visitas e formulações de projetos para países africanos fizeram com que Freire conseguisse adentrar na situação e no contexto vivenciado pela população desses países. Dessa forma, Freire identifica as formas de exploração e poder que atuam em um processo mascarado por meio de ideologias que mantém a alienação, o desconhecimento e a mistificação desempenhados de maneira intencional sobre o oprimido. A ideologia colonialista possuía os seguintes objetivos: 


\section{artigos}

Abdias do Nascimento e Paulo Freire: dizeres, saberes e experiências na África Ocidental

(1975-1988)

Reproduzindo, como não podia deixar de ser, a ideologia colonialista, procurava incutir nas crianças e nos jovens o perfil que deles fazia aquela ideologia. $O$ de seres inferiores, incapazes, cuja única salvação estaria em tornar-se "brancos" ou "pretos de alma branca". (...) A história dos colonizados "começava" com a chegada dos colonizadores, com sua presença "civilizatória"; a cultura dos colonizados, expressão de sua forma bárbara de compreender o mundo. Cultura, só a dos colonizadores. A música dos colonizados, seu ritmo, sua dança, seus bailes, a ligeireza de movimentos de seu corpo, sua criatividade em geral, nada disto tinha valor. Tudo isto, quase sempre, tinha de ser reprimido e, em seu lugar, imposto o gosto da Metrópole, no fundo, o gosto das classes dominantes metropolitanas (FREIRE, 1978, p. 20).

Muitos são os meios usados pelo dominador para solidificar a opressão. Segundo Freire, vários desses caminhos estão envoltos na teoria da ação antidialógica, que é baseada na necessidade de conquista e na ação dos dominadores, presente em seu livro Pedagogia do Oprimido:

O primeiro caráter que nos parece poder ser surpreendido na ação antidialógica é a necessidade da conquista. $\mathrm{O}$ antidialógico, dominador, nas suas relações com o seu contrário, o que pretende é conquistá-lo, cada vez mais, através de mil formas. Das mais duras às mais sutis. Das mais repressivas às mais adocicadas, como o paternalismo. Todo ato de conquista implica num sujeito que conquista e num objeto conquistado. (...) O antidiálogo se impõe ao opressor, na situação objetiva de opressão, para, pela conquista, oprimir mais, não só economicamente, mas culturalmente, roubando ao oprimido conquistado sua palavra também, sua expressividade, sua cultura (FREIRE, 1987, p. 101).

Além da conveniência da conquista, o dominador também faz uso do dividir, para manter a opressão, da manipulação e da invasão cultural:

Na medida em que as minorias, submetendo as maiorias a seu domínio, as oprimem, dividi-las e mantê-las divididas são condição indispensável à continuidade de seu poder. Não se podem dar ao luxo de consentir na unificação das massas populares, que significaria, indiscutivelmente, uma séria ameaça à sua hegemonia. (...) Outra característica da teoria da ação antidialógica é a manipulação das massas oprimidas. 


\section{artigos}

Elisa Ferreira Teixeira

Através da manipulação, as elites dominadoras vão tentando conformar as massas populares a seus objetivos. E, quanto mais imaturas, politicamente, estejam elas (rurais ou urbanas) tanto mais facilmente se deixam manipular pelas elites dominadoras que não podem querer que se esgote seu poder. (...) Finalmente, surpreendemos na teoria da ação antidialógica, uma outra característica fundamental, - a invasão cultural que, como as duas anteriores, serve à conquista. Desrespeitando as potencialidades do ser a que condiciona, a invasão cultural é a penetração que fazem os invasores no contexto cultural dos invadidos, impondo a estes sua visão do mundo, enquanto Ihes freiam a criatividade, ao inibirem sua expansão. Neste sentido, a invasão cultural, indiscutivelmente alienante, realizada maciamente ou não, é sempre uma violência ao ser da cultura invadida, que perde sua originalidade ou se vê ameaçado de perdê-la (FREIRE, 1987, p. 101-113).

Freire abomina qualquer tipo de discriminação, racismo e desigualdade. Deixa sempre explícito sua indignação com atitudes que inferiorizam o outro e salienta que qualquer discriminação é imoral e lutar contra ela é um dever. É inaceitável qualquer prática preconceituosa e/ou discriminatória, pois isto fere princípios básicos preconizados por Paulo Freire, como: a fé nos seres humanos, a luta pela igualdade, a humildade, a ética, a autonomia e o bom senso. A educação, partindo da realidade do educando, admite a não superioridade de determinada cultura em relação a outra. Portanto, a presença da diversidade cultural deve ser respeitada e debatida.

Sabendo dos objetivos da ideologia colonialista, a educação é um importante caminho para a descolonização das mentes, e por isso o educador precisa desenvolver uma prática educativa que funcione como uma contraideologia, ou seja, a partir do momento que se identifica os meios de opressão a solução é trabalhar com o seu oposto. Então, se o opressor aliena, mistifica, preza pelo desconhecimento, pela cultura do silêncio, o educador radical estabelecerá uma relação dialógica com o educando, trabalhará com a consciência crítica e a conscientização, a igualdade e a confiança no convívio escolar, entre outros, e com isso teremos as bases que sustentarão a transformação social. 


\section{artigos}

Abdias do Nascimento e Paulo Freire: dizeres, saberes e experiências na África Ocidental (1975-1988)

Abdias do Nascimento também tem opiniões próprias sobre o colonialismo e o racismo. Nas suas várias obras, Nascimento desmascara importantes pontos sobre o processo colonizador, e também demonstra como cada um desses pontos inseriu-se na vida da população negra no seu livro O genocídio do negro brasileiro. Um dos mais importantes pontos abordados pelo autor é uma questão abordada por diversos intelectuais: a ideia de que a escravidão no Brasil foi mais humanitária, benevolente, o negro foi visto como dócil e obediente, e por conta disso foi possível o desenvolvimento de um convívio harmônico entre o colonizador e o colonizado. Há nitidamente a tentativa de mascarar a ideologia imperialista e distorcer o passado africano, e também podemos enxergar a minimização da culpa do opressor e a justificação do sistema escravocrata. Mas, sabe-se que a realidade da colonização e da escravidão foi outra:

Essa rabulice colonizadora pretendia imprimir o selo de legalidade, benevolência e generosidade civilizadora à sua atuação no território africano. Porém, todas essas e outras dissimulações oficiais não conseguiram encobrir a realidade, que consistia no saque de terras e povos, e na repressão e negação de suas culturas - ambos sustentados e realizados, não pelo artifício jurídico, mas sim pela força militar imperialista (NASCIMENTO, 2002, p. 89-90).

Nascimento também discute sobre a perseguição da cultura africana no Brasil. Inicialmente, ele deixa nítida a visão que se propagava até então, que trouxe a imagem de um país que ajudou a cultura afro-brasileira a resistir e a continuar "viva" em nosso meio. Contudo, a realidade histórica é bem diferente. Foram utilizados diversos meios pela sociedade dominante para acabar com a cultura e a história negro-africana:

Entre os instrumentos usados pelo poder escravizador estava a Igreja Católica que, absolutamente, não é responsável pela persistência das religiões de origem africana (...). Essa Igreja possuía escravos com fins lucrativos e perseguia e atacava as crenças religiosas africanas durante séculos e até os dias atuais (NASCIMENTO, 2002, p. 151152). 


\section{artigos}

Elisa Ferreira Teixeira

Por conta das privações e negações a que estavam submetidos os afro-brasileiros, muitas foram as formas de resistência utilizadas para fazer com que as suas culturas fossem preservadas. Porém, nem todos os africanos conseguiram mantê-las vivas, pois eram vítimas permanentes da violência, suas instituições culturais se desintegraram no estado de choque a que foram submetidas (NASCIMENTO, 2002, p. 153). Apesar das limitações impostas pela sociedade dominante às raízes e culturas africanas, muitas das suas experiências e saberes extrapolaram as "fronteiras". Como exemplo temos as suas obras artísticas: talhas, esculturas, entre outros. Contudo, essas criações passaram a ser vistas como sendo inferiores às demais, e por isso são menosprezadas regularmente:

Aos olhos da cultura dominante, os produtos da criatividade religiosa afro-brasileira e dos africanos de modo geral não passavam de curiosidade etnográfica- destituído de significação artística ou ritual. (...) Por sua vez, no sentido de "compreender" o trabalho criativo do africano ou afro-brasileiro, os críticos formados sobre os critérios estranhos da sociedade dominante branca dominante necessitam preliminarmente esvaziá-los de seu valor intrínseco, conseguindo perceber neles somente aquelas características recomendadas pelo etnocentrismo original que os inspira e guia na classificação do que seria "primitivo", "cru", "tosco" ou "arcaico". Emerso de um contexto espiritual, social e religioso e de uma herança formal específica que se conjugam para compor uma perspectiva senão oposta, pelo menos radicalmente diferindo daquela de essência ocidental ou ocidentalizada, o produto artístico negro, por tudo isso, tem sido marginalizado, banalizado ou recebido uma forma de "valorização" que mais se confunde com o desprezo e o desdém (NASCIMENTO, 2002, p. 172).

Nascimento também coloca a discriminação como um dos pontos centrais de suas obras, pelo fato das feridas da discriminação ainda estarem "abertas" na realidade social do nosso país:

Se os negros vivem nas favelas porque não possuem meios para alugar ou comprar residência nas áreas habitáveis, por sua vez a falta de dinheiro resulta da discriminação no emprego. Se a falta de emprego é por causa de carência de preparo técnico e de instrução adequada, a falta desta aptidão se deve à ausência de recurso financeiro. Nesta teia, o afro-brasileiro se vê tolhido de todos os lados, prisioneiro 


\section{artigos}

Abdias do Nascimento e Paulo Freire: dizeres, saberes e experiências na África Ocidental

de um círculo vicioso de discriminação - no emprego, na escola - e trancadas as oportunidades que lhe permitiram melhorar suas condições de vida, sua moradia, inclusive (NASCIMENTO, 2002, p. 131).

Diante do que foi exposto, percebe-se a importância das denúncias feitas por Nascimento, declarações estas que mostram a urgência para repensar a história e a maneira de lidar com as questões africanas. As alegações também deixam nítidas a necessidade de lutar contra a discriminação racial no Brasil e dar maior visibilidade ao negro numa sociedade que ainda convive com as marcas do racismo. Ao repensar e refletir sobre a história negro-africana, a população proporcionará a existência de uma sociedade em que a convivência e o respeito pela diversidade sejam realmente colocados em prática. A partir do desenvolvimento de atitudes de tolerância e respeito à diversidade, teremos a solidificação do direito à igualdade de oportunidades e do direito à participação na comunidade, e com isso serão constituídos pilares fundamentais para a existência de qualquer sociedade.

\section{Considerações finais}

O estudo do colonialismo e do racismo desvenda a realidade da opressão e da violência, e faz com que se tenha consciência dos meios usados para a criação de valores, concepções, atitudes preconceituosas e preceitos que favorecessem apenas às classes dominadoras da sociedade. Paulo Freire e Abdias do Nascimento identificam os meios de opressão, as ideologias, a falsa generosidade do dominador, a valorização do silêncio, do desconhecimento e da alienação do oprimido como formas de manutenção dos privilégios dos detentores do poder. E mais do que isto, eles sugerem maneiras e projetos para a população negra libertar-se da opressão e do silêncio impostos pela sociedade dominante.

Com base no que foi demonstrado, é evidente a relevância que tanto Paulo Freire quanto Abdias do Nascimento possuem para o contexto adotado no artigo. Além de discutirem importantes pontos acerca das questões raciais, eles também ajudaram no combate ao racismo e ao colonialismo. A partir das narrativas e experiências desses dois intelectuais temos um novo olhar sobre a história e, consequentemente, a reafirmação da importância dos testemunhos e vozes do protagonismo 


\section{artigos}

Elisa Ferreira Teixeira

antirracista. Freire nos demonstra o contexto e a situação da África e dos seus filhos no processo emancipatório, evidenciando os obstáculos e as soluções usadas para afastar a mancha que o colonialismo deixou. Nascimento nos traz visões e opiniões sobre a realidade do negro no Brasil, explicitando as adversidades e os estigmas que fazem parte do dia-a-dia da população afrobrasileira. Assim sendo, cada um, da sua maneira, demonstra questões de peso relevante para a história: a visualização da situação do negro em ambos os lados do Atlântico e os caminhos usados para a melhoria de vida e valorização da cultura e da tradição das populações africanas e afrobrasileiras.

\section{Referências bibliográficas}

CÉSAIRE, Aimé. Discurso sobre o colonialismo. Lisboa: Sá de Costa Editora, 1978.

FERNANDES, Florestan. O negro no mundo dos brancos. 2. ed. Global: São Paulo, 2007.

FLORES, Elio Chaves. Historiografia africanista e historiografia africana: leituras comparativas e epistemológicas. In: Anais Eletrônicos do XVI Encontro Estadual de História. Campina Grande: ANPUHPB, p. 633-644, 2014. ISSN: 2359-2796.

A nação amada, a nação fustigada: percursos, racionalidades e variações da história comparada. João Pessoa: PPGH/DH, 2014.

FREIRE, Paulo. Cartas à Guiné-Bissau: registros de uma experiência em processo. 4.ed. Rio de Janeiro: Paz e Terra, 1978.

Pedagogia do oprimido. 17.ed. Rio de Janeiro: Paz e Terra, 1987.

; GUIMARÃES, Sérgio. A África ensinando a gente: Angola, Guiné-Bissau, São Tomé e Príncipe. São Paulo: Paz e Terra, 2003.

GADOTTI, Moacir et al. Paulo Freire - uma biobibliografia. São Paulo; Brasília: Cortez; Instituto Paulo Freire; UNESCO, 1996.

GILROY, Paul. O atlântico negro: modernidade e dupla consciência. São Paulo: Editora 34, 2001. 


\section{artigos}

Abdias do Nascimento e Paulo Freire: dizeres, saberes e experiências na África Ocidental (1975-1988)

HOFBAUER, Andreas. O conceito de "raça" e o ideário do "branqueamento" do século XIX - bases ideológicas do racismo brasileiro. Teoria e Pesquisa, São Paulo, vol. 1, n.42, p. 63-110, 2003.

MAZRUI, Ali A.; WONDJI, Christophe. (Ed.). História geral da África, VIII: África desde 1935. Brasília: UNESCO, 2010.

M'BOKOLO, Elikia. África negra: história e civilizações. Tradução de Manuel Resende. Salvador: EDUFB; São Paulo: Casa das Áfricas, 2011.

MEMMI, Albert. Retrato do colonizado precedido de retrato do colonizador. Rio de Janeiro: Civilização Brasileira, 2007.

MESQUIDA, Peri; PEROZA, Juliano; AKKARI, Abdeljalil. A contribuição de Paulo Freire à educação na África: uma proposta de descolonização da escola. Educação \& Sociedade, Campinas, v. 35, n. 126, p. 95-110, jan./mar. 2014.

NASCIMENTO, Abdias do. O Brasil na mira do pan-africanismo. 2.ed. Salvador: EDUFBA: CEAO, 2002. (Org.). O Negro Revoltado. $2^{\mathrm{a}}$ Ed. Rio de Janeiro: Nova Fronteira, 1982.

Teatro experimental do negro: trajetória e reflexões. Estudos avançados, São Paulo, v. 18, n. 50, p. 271-284, jan./abr. 2004.

NUNES, Sylvia da Silveira. Racismo no Brasil: tentativas de disfarce de uma violência Explícita. Psicol. USP [online]. 2006, vol.17, n.1, pp.89-98. ISSN 0103-6564.

PEREIRA, Amilcar Araujo. O mundo negro: relações raciais e a constituição do movimento negro contemporâneo no Brasil. Rio de Janeiro: Pallas, 2013.

; VITTORIA, Paolo. A luta pela descolonização e as experiências de alfabetização na GuinéBissau: Amílcar Cabral e Paulo Freire. Est. Hist., Rio de Janeiro, vol. 25, n. 50, p. 291-311, jul./dez. 2012. 


\section{artigos}

Elisa Ferreira Teixeira

PEREIRA, André Luis. O pensamento social e político na obra de Abdias do Nascimento. 2011. 105 f. Dissertação (Mestrado em Sociologia) - Instituto de filosofia e ciências humanas, Universidade Federal do Rio Grande do Sul, Rio Grande do Sul. 2011.

PEREIRA, Olga Maria Lima. A dor da cor: reflexões sobre o papel do Negro no Brasil. Cadernos Imbondeiro, João Pessoa, v.2, n.1, p. 1-10, 2012.

PEREIRA, José Maria Nunes. Colonialismo, Racismo, Descolonização. Centro de Estudos Afro-Asiáticos, Conjunto Universitário Cândido Mendes, Rio de Janeiro, ano 1, n. 2, maio-agosto, 1978.

RÛSEN, Jorn. Historiografia comparativa intercultural. In: MALERBA, Jurandir. (Org.). A história escrita: teoria e história da historiografia. São Paulo: Contexto, 2006, p. 115-137.

SEMOG, Éle; NASCIMENTO, Abdias. O griot e as muralhas. Rio de Janeiro: Pallas, 2006.

TRAPP, Petry Rafael. Movimento negro, "raça" e transnacionalidade: apontamentos sobre o pensamento antirracista brasileiro. In: Anais eletrônicos do XI Encontro Estadual de História. Rio Grande: ANPUH- RS, p. 905-914, 2012. ISSN: 2178-1761.

VISENTINI, Paulo Fagundes; RIBEIRA, Luiz Dario Teixeira; PEREIRA, Analúcia Danilevicz. História da África e dos africanos. Petrópolis, RJ: Vozes, 2013. 